\title{
Assessing the Determinants of Exchange Rate Stability: An Empirical Evidence in Malaysia
}

\author{
Rohaiza Kamis ${ }^{1}$, Mohd Isham Abidin ${ }^{2}$, Shafinar Ismail ${ }^{3}$, Mohd Halim Mahphoth ${ }^{4}$, Amsyar \\ Haziq bin Arifin ${ }^{5}$ \\ $\left\{\right.$ rohai451@uitm.edu.my ${ }^{1}$ \} \\ Universiti Teknologi MARA, Malaysia ${ }^{1,2,3,4,5}$
}

\begin{abstract}
This study empirically examined the effect of macroeconomic variables on the exchange rate of Malaysia Ringgit against the US dollar for the past 14-year on monthly basis from July 2005 to July 2019. The Real Exchange Rate of Malaysia Ringgit against the US dollar (EXC) has been used as a dependent variable where the other four macroeconomic components had been classified as the export (EXP), import (IMP), inflation (INF), and interest rate (INT) as independent variables. The result shows that the export (EXP) is positively significant at level 5\%, the import (IMP) is negatively significant at $5 \%$ level of significance with the real exchange rate (EXC), the inflation (INF) is also negatively significant at $1 \%$ level of significance, and interest rate (INT) is not significant. The EXP has positively forced the exchange rate means that when the values of this variable increase the value of exchange will be increasing but in the case of IMP and INF is vice versa. The inflation is the most significant macroeconomic determinant of the exchange rate. These findings may give some overview of policy implications to the policymakers in optimizing the effects of macroeconomic variables towards the stability of the exchange rate.
\end{abstract}

Keywords: Macroeconomic Variables, Exchange Rate, Multiple Linear Regression

\section{Introduction}

The exchange rate could be a profoundly sensitive economic variable for internal and external factors, particularly because of the extension of the part of foreign trade in economic growth and the development of international financial markets. This cost is drastically diverse in its substance and its significance from other economic variables. A high currency exchange rate is also seen as an indication of economic growth. This may transform into a sign of national pride. The government also worry if they see the exchange rate weakening. They refer to a high rate of exchange as a sign of economic prosperity. Monetary policy also can be defined as accommodative in this respect if the interest rate is intended to produce economic growth. Whether it is meant to counter growth (or, more often, counter inflation), it may increase interest rates to curb borrowing. Those steps balance economic growth and keep inflation low. The macroeconomic indicators have a large impact on the exchange rate, through its direct and indirect relationship. In this study, the economic variables are namely interest rate, inflation, export, and import. It is of incredible significance as an instrument of macroeconomic apparatuses, even though the degree of impact on the economy varies depending on the connected exchange systems, which is due to the variety of the determinants of each framework. Besides, most of the countries were set their currencies based on the gold prices and changed 
into the basis of USD after the Second World War. The currency devaluation has a variety of implications for economic growth. The exchange rate for USD against MYR means that the quantity of one currency can be exchanged for another currency unit, while the real exchange rate defines how many products or services can be sold for one of those goods or services in another country.

Management of exchange rates has long been a topical concern among economists and policymakers. It began largely with the fall of the Gold standard in the 1930s and the subsequent introduction of the Bretton Wood Adjustment Program from the 1940s, through the adoption of the developing nation's flexible exchange rate in 1970 and economic changes in the 1970s. Flexible exchange rates are followed by exchange rate fluctuations, making it the key subject in the debate due to its effect on the business result as business partners of nations will prefer a steady exchange rate to a variable one. Previous studies also recognized the importance of maintaining a stable exchange rate in boosting economic development. Exchange-rate volatility creates confusion and risk in investment decisions with destabilizing macroeconomic output impacts [1].

According to Devereux's [2] survey result, under short-run sticky prices and high capital mobility (Mundell-Fleming-Dornbusch type models), the nominal exchange rate is more volatile than its underlying fundamentals over the short-term, but as long-term costs change, the real exchange rate relies on its long-term equilibrium level to the same magnitude. In conjunction, the real exchange rate merges with the Purchasing Power Parity (PPP) which implies that the fundamental macro-economic variable of the inflation rate has no impact on the real exchange rate. In addition to Chowdhury [3], Australia's real exchange rate is increased in the long run by trade, government expenditures, and net foreign liabilities, but in contrary, the rate is depreciated by interest rate differential adjustments, trade openness, and long-term technological and productivity improvements. Furthermore, export and import are also important variables that give an impact on the exchange rate [4]. The result shows that the MYR exchange rate was positively impacted by trade openness, current account balance, and sovereign debt and negatively impacted by the crude oil price. Based on these findings, policymakers must consider planning favorable trade arrangements that propose these trade accomplices to increase trade relations with Malaysia, particularly within the domain of Malaysia's goods and services trades. Choudhry and Hassan [5] found that exchange rate volatility significantly impacted UK imports to China, South Africa, and Brazil. They also suggested exchange rate volatility as a significant determinant of trade. Nishimura and Hirayama [6] also contended the same through their study on volatility in the exchange rate between Japan and China. Their results showed that exchange rate volatility negatively impacted China's exports to Japan. Given these arguments, the motivation of this study is to assess the determinants of interest rate, inflation rate, export, and import on the Malaysian exchange rate.

\section{Research Method}

The study used monthly data collected from various sources such as the DataStream and Thompson Reuters for fourteen (14) years, from the period of 2005 to 2019. The time-series data were analyzed using Econometric Views (E-views 9) software to test the regression analysis and to answer the research objectives. The data was converted into a logarithm to standardize the entire figures. The model employed a clearer understanding of the strengths and structures of the data observed. The tests list includes the Unit Root test, Descriptive Statistics, 
and Multiple Linear Regression. The Unit Root Test was conducted using the Augmented Dickey-Fuller (ADF) statistics to test the stationarity of the data. Many economic and financial time series data show a trendy or non-stationary trend in the mean and an infinite variance [7]. Thus, unit-roots can cause unpredictable and bias results in time series analysis; and spurious correlations are very likely to emerge in non-stationary data. The smaller the value (negative value), the stronger the evidence for the data to be stationary [7][8]. A multiple regression model was used to test the study hypothesis. The empirical model that was used for the analysis was developed as follows:

$$
\mathrm{EXC}=\alpha+\beta 1 \mathrm{EXP}+\beta 2 \mathrm{IMP}+\beta 3 \mathrm{INF}+\beta 4 \mathrm{INT}+\varepsilon
$$

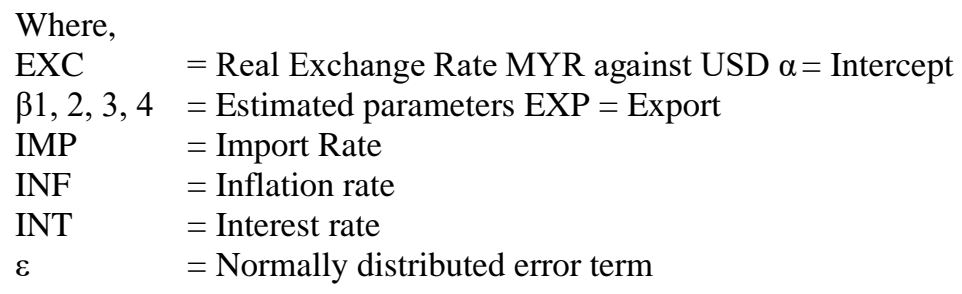

The observation of the dependent variable (Y) was represented by the Real Exchange Rate of Malaysia Ringgit against the US dollar (EXC). Meanwhile, the independent variables were represented by the selected macroeconomic determinants (INT, INF, EXP, and IMP) based on previous literature. The associated regression coefficients were represented by beta ( $ß)$. Several diagnostic studies have been done to ensure that the proposed model in this analysis closely resembles the time series under consideration by subjecting the calibrated model to a set of analytical measures, such as the Jarque-Bera Normality Test, the BreuschGodfrey LM Test, the White Test, the Ramsey Reset Test, and the Multicollinearity Test.

\section{Result and Discussion}

\subsection{Unit Root Test}

Firstly, the Unit Root Test was conducted using the Augmented Dickey-Fuller (ADF) statistics to test the stationarity of the data. The outcomes obtained from the Augmented-Dickey Fuller Test, as presented in Table 1, indicates that the data regarding The Real Exchange Rate of Malaysia Ringgit against US dollar (EXC), export (EXP), import (IMP), inflation (INF), and interest rate (INT), are all stationary at the level of significance at first difference whereby all the p-values are less than 0.01 of critical values.

Table 1. Augmented Dickey-Fuller (ADF) Test

\begin{tabular}{ccccc}
\hline \multirow{2}{*}{ Variable } & \multicolumn{3}{c}{ Augmented Dickey-Fuller Test } \\
\cline { 2 - 5 } & Level & \multicolumn{2}{c}{ First difference } \\
\cline { 2 - 5 } & Intercept & Intercept with trend & Intercept & Intercept with trend \\
\hline \multirow{2}{*}{ EXC } & -0.880079 & -1.777180 & -11.17483 & -11.23189 \\
& $(0.7926)$ & $(0.7116)$ & $(0.0000)^{* * *}$ & $(0.0000)^{* * *}$
\end{tabular}




$\begin{array}{lcccc}\text { EXP } & -0.927867 & -3.174221 & -14.45775 & -4.825254 \\ & (0.7774) & (0.0933) & (0.0000)^{* * *} & (0.0006) * * * \\ \text { IMP } & -0.933187 & -4.320308 & -14.58881 & -14.55257 \\ & (0.7756) & (0.0038)^{* * *} & (0.0000)^{* * *} & (0.0000)^{* * *} \\ \text { INF } & -0.761533 & -3.931063 & -9.462883 & -9.443683 \\ & (0.8268) & (0.0128)^{* * *} & (0.0000)^{* * *} & (0.0000)^{* * *} \\ \text { INT } & -2.402178 & -2.376375 & -8.567133 & -8.551722 \\ & (0.1427) & (0.3905) & (0.0000)^{* * *} & (0.0000)^{* * *}\end{array}$

Note: $* * *$ Significant at the $1 \%$ level, $* *$ Significant at the $5 \%$ level, $*$ Significant at the $10 \%$ level

\subsection{Descriptive Statistics}

Table 2 shows the summary of descriptive statistics of monthly data on macroeconomic variables from the year 2005 to 2019 with a total number of 169 observations.

Table 2. Descriptive Statistics

\begin{tabular}{lccccc}
\hline & LEXC & LEXP & LIMP & LINF & LINT \\
\hline Mean & 1.269587 & 10.99758 & 10.83320 & 4.656219 & 1.096225 \\
Median & 1.250274 & 10.98614 & 10.82422 & 4.652054 & 1.098612 \\
Maximum & 1.499511 & 11.48372 & 11.29646 & 4.799914 & 1.258461 \\
Minimum & 1.085628 & 10.51874 & 10.21692 & 4.473922 & 0.688135 \\
Std. Dev. & 0.118015 & 0.194357 & 0.230123 & 0.095732 & 0.146509 \\
Skewness & 0.308126 & 0.200903 & 0.001434 & -0.097407 & -1.575917 \\
Kurtosis & 1.821173 & 2.610185 & 2.426962 & 1.879419 & 5.226920 \\
Jarque-Bera & 12.45953 & 2.206880 & 2.312349 & 9.109491 & 104.8731 \\
Probability & $(0.001970)^{* * *}$ & $(0.331728)$ & $(0.314688)$ & $(0.010517)^{* *}$ & $(0.000000)^{* * *}$ \\
Sum & 214.5603 & 1858.591 & 1830.811 & 786.9010 & 185.2621 \\
Sum Sq. Dev. & 2.339838 & 6.346132 & 8.896714 & 1.539649 & 3.606084 \\
Observations & 169 & 169 & 169 & 169 & 169 \\
\hline
\end{tabular}

Note: $* * *$ Significant at the $1 \%$ level, $* *$ Significant at the $5 \%$ level, $*$ Significant at the $10 \%$ level.

The mean for all variables is positive ranging from 1.096225 to 10.99758 . The mean for all the variables is greater than the median value. This indicates that the distribution of data for all the variables appears to be skewed to the left. The dispersion of the data is reflected by the measure of standard deviation. All the variables are spread within the range of 0.095732 to 0.230123 . The import (IMP) variable recorded the highest at 0.230123 while the inflation rate (INF) has the lowest at 0.118015 . In terms of skewness, the inflation and interest rate are negatively skewed at 0.097407 and 1.575917 respectively while for the other variables they are positively skewed. The Kurtosis result for the exchange rate, export, import, and inflation shows that the variables are measured as a platykurtic distribution with a value of less than 3 , at kurtosis values of $1.821173,2.610185,2.426962$, and 1.879419 respectively. The platykurtic distribution is represented with less peaked in the mean and thinner tails compared to the normal distribution (i.e., flatter distribution). Meanwhile, the leptokurtic distribution was reflected in the interest rate with the values of 5.226920; which is more than 3 . This indicates that the distribution of the data has fatter tails and sharper peak compared to the normal distribution (i.e., peaked distribution). Finally, based on the Jarque-Bera test, the data for export and import are normally distributed since the p-value is more than 0.1 . However, the data distribution of the 
exchange rate, inflation, and interest rate are not normally distributed since the p-value is less than 0.1. This reflects that the data for EXC, INF, and INT might have outliers and therefore should be cautiously interpreted.

\subsection{Regression Analysis}

Based on the regression analysis result shown in Table 3, the export has a positive and significant relationship with the exchange rate with less than 0.05 critical values. However, the interest rate is found to be an insignificant determinant in influencing the exchange rate as the p-value is more than 0.10 . The inflation and import have a negative and significant relationship with the exchange rate with less than 0.05 critical value. The inflation has the highest coefficient beta value at 0.607062 , indicating that inflation is the most significant macroeconomic determinant of the exchange rate. Precisely, $25.71 \%$ of the variation in the exchange rate can be explained by the export, import, inflation, and interest rate. The subsequent $74.29 \%$ of the difference in MYR performance versus USD is explained by other variables, such as GDP, oil price and the financing rate, which are excluded from the model to be generalized for the future analysis. Overall, the proposed model of this study is fit and acceptable since the p- value of the F-test is 0.00000 in which the value is lower than 0.01 . The output of the regression analysis is presented as per below equation:

$\mathrm{EXC}=-2.414772+0.387994 \mathrm{EXP}-0.324959 \mathrm{IMP}-0.607062 \mathrm{INF}+0.101342 \mathrm{INT}+\varepsilon$

Table 3. Multiple Linear Regressions Model Empirical Result

\begin{tabular}{lcc}
\hline \multicolumn{1}{c}{ Item } & Coefficient Value & p-value \\
\hline$\beta 0$ & -2.414772 & 0.0000 \\
Export (EXP) & 0.387994 & $0.0216^{* * *}$ \\
Import (IMP) & -0.324959 & $0.0446^{* *}$ \\
Inflation (INF) & -0.607062 & $0.0035^{* * *}$ \\
Interest Rate (INT) & 0.101342 & 0.1101 \\
R-Squared & 0.283871 & \\
Adjusted R-Squared & 0.257100 & \\
Number Observation & 169 & 0.00000 \\
F-statistics & 16.25223 & \\
\hline Note: $* * *$ Significant at the 1\% level, ** Significant at the 5\% level, * Significant at the $10 \%$ level
\end{tabular}

To answer the research objectives, Table 4 below shows the list of hypotheses and the verdicts of the hypotheses testing.

Table 4. Summary of Hypothesis Testing Diagnostic Tests Diagnostic Tests

Hypothesis Findings

H1: There is a significant relationship The first hypothesis for this study is accepted. between the export (EXP) and the The result of the export is significant and has exchange rate (MYR against USD). $\quad$ a positive relationship with the exchange rate. This is due to the escalating trend of export for Malaysia. The result of this study is similar to previous studies done by Atta [9]. 
H2: There is a significant relationship The second hypothesis is accepted for the between the import (IMP) and the study and aligned with some previous studies exchange rate (MYR against USD). done by Butt et al. [10]. The result for the import is significant and has a negative relationship with the exchange rate. This is due to the rising trend in the volatile price of oil, which permits the Malaysian oil industries to import more than just a dollar to pay for the higher cost of imported oil, which ultimately contributes to the deterioration of the Malaysian Ringgit.

H3: There is a significant relationship The third hypothesis for this study is between inflation (INF) and the exchange accepted. The result for inflation is rate (MYR against USD). significant and has a negative relationship with the exchange rate. The result of this study is similar to previous studies done by Mahammad et al. [11], Honohan et al. [12]. The inflation rate has a negative influence on the exchange rate which is consistent with literature either theories or applied cases. An increase in the inflation rate means a decrease in the purchasing power of the currency and consequently, it depreciates against the other countries' currencies.

H4: There is a significant relationship The fourth hypothesis is rejected. The interest between the interest rate (INT) and the rate does not appear to be materially exchange rate (MYR against USD). significant towards the exchange rate.

Several analytical tests were performed to ensure that the proposed model in this study accurately reflects the time series under consideration by subjecting the calibrated model to a variety of statistical tests as outlined in Table 5.

Table 5. Results for the Diagnostic Tests on Multiple Linear Regression Model

\begin{tabular}{cc}
\hline Diagnostic Tests & p-value \\
\hline (i) Jarque-Bera Normality Test & 0.0052 \\
(ii) Breusch-Godfrey LM Test & 0.0000 \\
(iii) White Test & 0.0000 \\
(iv) Ramsey's Reset Test & 0.0000 \\
\hline (v) Multicollinearity Test & \\
Independent Variable & 0.492907 \\
a. EXP & 0.467231 \\
b. IMP & 0.498187 \\
c. INF & 0.156183 \\
d. INT & \\
\hline
\end{tabular}

The data were subjected to a normality test because the regression analysis assumed that the data were normally distributed. If the data is not normal, then the results will be misleading. Hence, the first diagnostic checking that was conducted was the Jarque-Bera test to determine 
whether the model error terms were normally distributed [13]. It can be concluded that the multiple linear regression model error terms were normally distributed with a p-value of 0.0052 , which was at $1 \%$ significant level with $99 \%$ confidence level.

After conducting the Jarque-Bera test, the Breusch-Godfrey LM Test was conducted to find out the existence of any autocorrelation problem between variables. Autocorrelation refers to time series correlation and can be alluded to as lagged correlation or serial correlation [13]. The result in Table 5 shows a p-value of 0.0000 which was a $1 \%$ significant level with a $99 \%$ confidence level. The result indicates that no autocorrelation problem existed. Therefore, the data used were serially independent of the error term.

Next, the White Test was performed to discover heteroscedasticity problems. When the error term differs across the observations, heteroscedasticity is present [13]. The standard errors of the estimates are distorted if heteroscedasticity exists. Based on Table 5, the p-value for this test was 0.0000 , which was significant at the $1 \%$ level with a $99 \%$ level of confidence. The outcome of the white test provides evidence that the null hypothesis was not rejected. This indicates that the model is estimated to have a heteroscedasticity problem. Therefore, the findings produced by the model may be distorted and should be cautiously interpreted.

Next, the Ramsey's Reset Test was carried out to determine whether the model was correctly specified. Based on the result in Table 5 , the p-value for t-statistic was at 0.0000 and shows the evidence fails to reject the null hypothesis at a $99 \%$ confidence interval. It means that is misspecification of the functional form used on the model. Therefore, the results estimated from the model could be biased and should be cautiously interpreted.

Finally, the Multicollinearity Test was conducted using the variance inflation factors (VIF) to determine the correlation between independent variables. The result of VIF for all variables was less than 10 , indicating a high-quality result where there was no serious multicollinearity problem [13].

\section{Conclusion}

One of the country's most significant determinations is the exchange rate relative to economic development. The exchange rate plays a vital role in a country to level the trade which is essential for every competitive market economy. The empirical findings revealed that the exchange rate (MYR against USD) is driven primarily by three economic variables which are export, import, and inflation. Inflation has been identified as the most significant factor that leads to the fluctuation of the exchange rate. However, the interest rate does not give any significant impact on the exchange rate (MYR against USD).

Based on the empirical results, this implies that export has a positive significant relationship towards exchange rate (MYR against USD). This is an indicator of economic openness relating to export and its degree of globalization, implying that the more economies open to international trade, the stronger the currency. That can be justified as the country becomes much more prominent in international trade in this scenario, resulting in a positive economy and a stronger local currency as a consequence. Besides, encouraging exports by giving support either directly or indirectly to the export industries will give them a competitive advantage over the other countries' products as well as improve the performance of the home currency.

On the other hand, the results show that the import had a negative effect on the exchange rate. Higher import levels and a rising trade deficit can have a negative impact on the country's exchange rate. If too many imports originate in a country as opposed to its exports, the trade 
balance of a nation may be skewed and its currency may be devalued. In particular, a country must maintain an acceptable balance of imports and exports. The import and export activity of a country will affect the country 's GDP, exchange rate, inflation and interest rates.

Nevertheless, inflation has a negative significant relationship with the exchange rate and the most significant macroeconomic determinant of the exchange rate. Traditional currency theory states that a currency with higher inflation rates (and therefore higher interest rates) will depreciate against a currency with lower inflation and lower interest rates. The inflation rate of a country can has a significant impact on the value of the country's currency and the foreign exchange rate that it retains with other countries ' currencies. Inflation, however, is only one factor among many that affect the exchange rate of one country. Inflation is more likely to have a significant negative effect on currency than a considerable positive effect. Low inflation is driving demand. Long-term decisions are typically the most critical decisions made by individuals and companies alike: a decision to create a house, start a business, seek an education, own one's home. The degree of ambiguity about the future depends crucially on these decisions. Low and stable inflation is a macroeconomic stability indicator that largely contributes to people's and businesses' conviction in making investment decisions.

Certainly, this research had addressed many concerns for further review. Nevertheless, caution should be taken when interpreting the results, particularly given the limited availability, consistency, and comparability of the data. This would be useful if the data were made publicly accessible so that it could be used to get better results. Data in this study were limited to only 14-year on monthly basis from July 2005 to July 2019. It is also highly recommended to expand the observation period and includes more variables which are relevant for future research such as economic growth, trade balance (which demonstrates the level of demand for the goods and services of the country), government expenditure, and the debt level of the country all influence the value of a currency in question. The most influential interest determiner and currency exchange rate of a country is the currency's perceived desirability.

\section{References}

[1] I. Mahmood and S. Z. Ali, "Impact of exchange rate volatility on macroeconomic performance of Pakistan,” Int. Res. J. Financ. Econ., vol. 64, pp. 1450-2887, 2011.

[2] M. B. Devereux, "Real exchange rates and macroeconomics: evidence and theory," Can. J. Econ., pp. 773-808, 1997.

[3] K. Chowdhury, "Modelling the dynamics, structural breaks and the determinants of the real exchange rate of Australia," J. Int. Financ. Mark. Institutions Money, vol. 22, no. 2, pp. 343-358, 2012.

[4] N. H. Ab Razak, N. Nawawi, and C. M. Shan, "The Influence of Non-Parity Factors on the Exchange Rate of Malaysia Against Six Major Trading Partners," Malaysian J. Bus. Econ., p. 211,2020

[5] T. Choudhry and S. S. Hassan, "Exchange rate volatility and UK imports from developing countries: The effect of the global financial crisis," J. Int. Financ. Mark. Institutions Money, vol. 39 , pp. 89-101, 2015.

[6] Y. Nishimura and K. Hirayama, "Does exchange rate volatility deter Japan-China trade? Evidence from pre-and post-exchange rate reform in China," Japan World Econ., vol. 25, pp. 90-101, 2013.

[7] E. Zivot and J. Wang, "Unit root tests," Model. Financ. Time Ser. with S-PLUS®, pp. 111-139, 2006.

[8] D. A. Dickey and W. A. Fuller, "Likelihood ratio statistics for autoregressive time series with a unit root," Econom. J. Econom. Soc., pp. 1057-1072, 1981.

[9] E. Atta Arsanious, "Investigating the Determinants of Exchange Rate Stability: An Empirical Evidence,” Available SSRN 3546516, 2020. 
[10] S. Butt, S. Ramakrishnan, N. Loganathan, and M. A. Chohan, "Evaluating the exchange rate and commodity price nexus in Malaysia: evidence from the threshold cointegration approach," Financ. Innov., vol. 6, pp. 1-19, 2020.

[11] M. Mohsin, L. Naiwen, M. K. Majeed, and S. Naseem, "Impact of Macroeconomic Variables on Exchange Rate: An Evidence from Pakistan," in International Conference on Applied Economics, 2018, pp. 325-333.

[12] P. Honohan and P. R. Lane, "Exchange rates and inflation under EMU: an update," 2004.

[13] C. Brooks, "RATS Handbook to accompany introductory econometrics for finance," Cambridge Books, 2008. 